its withdrawal the fish-bone was coughed up and all the symptoms subsided.

The larynx remained red and swollen for a few days, but soon recovered its normal condition.

\title{
REMARKS ON A CASE OF ACUTE SUPPURATION OF THE MIDDLE EAR COMPLICATED BY SEPTIC MENINGITIS AND BRAIN ABSCESS.
}

\author{
By W. S. Syme, M.D.Edn., \\ Assistant Surgeon, Ear, Nose and Throat Hospital, Glasgow.
}

THE case which I wish first to relate and afterwards to offer some remarks upon was that of a school-boy, aged fourteen, whom I was asked to see by Dr. I'Anson, of Whitehaven, on March 5 of this year. On that day he had a discharge from his left ear of a week's duration. At first there was also a discharge from the right ear, but this had ceased after two days, and at the time of my visit this ear had recovered. The aural condition had followed a mild attack of influenza, which was especially prevalent in the school, and which in several cases was complicated by pneumonia. On February 28 this boy had a slight rigor with sickness, the temperature rising to $103^{\circ} \mathrm{F}$. It fell the next day and did not again rise till the morning of March 5, on which evening I first saw him. His condition then was : free discharge from left ear with a fair-sized perforation in the antero-inferior segment of the membrane. No pain over the mastoid and no tenderness on pressure, no severe headache, photophobia, ocular paralysis, or other symptom suggesting intra-cranial lesion. There was no mental dulling, the temperature was $100^{\circ} \mathrm{F}$., and the only anxious point was the somewhat slow pulse-70. I contented myself with recommending the ordinary antiseptic treatment of acute middleear suppuration together with a brisk purge. For two or three days he went on satisfactorily, and those in attendance on him thought he was quite in the way of recovery. On the third day, however, he seemed somewhat dull, answering only slowly when spoken to. At the same time tenderness appeared at the anterior part of the tip of the mastoid process, and also over the region of the antrum. The pulse-rate, too, had fallen to 60. On March $9 \mathrm{I}$ saw him again. We could find no other sign or symptom suggesting cerebral complication, except the mental dulness and slow pulse, but in view of these and the mastoid tenderness I decided 
to operate, and with the sssistance of Dr. I'Anson and Dr. Macpherson I opened the mastoid cells and antrum, doing the ordinary radical mastoid operation, and exposed the dura of the middle fossa above and the lateral sinus behind. Towards the inner side of the tip of the mastoid the cells had commenced to break down, but otherwise they were in a condition of intense inflammation such as I have never seen. In the attic and aditus some soft granulations were found. The dura in the middle fossa was more injected than usual and the pressure seemed slightly increased. On this account we discussed the advisability of incising the dura, but finally decided against doing so. The lateral sinus appeared healthy. Considering that it was possible that furthur operative measures would be required I left the wound open. The immediate result of this operation was an improvement in the mental condition, and an increase in the pulse-rate. On the 12th, however, the temperature began to rise, till on the morning of the 13 th it reached $1054^{\circ} \mathrm{F}$. On the evening of this day I saw him. Mental dulness had become more marked and was now accompanied by restlessness. He complained of pain in the lumbar region, and had once or twice had an involuntary evacuation from the bowels. The operation cavity was satisfactory. I exposed the sinus still further backward and downward. Posteriorly it appeared healthy, but toward the lower part the wall was greyer and apparently thicker than usual; it still contained fluid blood. Protecting the sinus with gauze, I opened the dura in the middle fossa, and at once gave exit to a small amount of pus. On passing a director backwards into the posterior part of the temporo-sphenoidal lobe it met with little resistance, and on withdrawing it shreds of what appeared to be hroken-down brain tissue escaped, giving one the impression of commencing necrosis or abscess of the surface of the lobe. After introducing a drain I cleansed the operation cavity and proceeded to open the sinus, expecting to find changes in the inner wall with mural thrombosis. The vessel bled freely, but on controlling the posterior part of the sinus the hæmorrhage from the lower part was seen to be slow and was easily stopped. Though no changes were detected in the inner coat of the sinus at the place where it was opened, it is probable that nearer, or in the jugular bulb, thrombosis had occurred. I did not, however, think it advisable to carry the dissection lower.

After two or three days the patient became comatose, and died just a week from these last operative measures. 
No post-mortem was obtained.

In looking back on this case several points of interest and worthy of consideration present themselves. There can be no doubt, I think, that the actual cause of death was septic meningitis, with acute necrosis or abscess of the temporo-sphenoidal lobe. The point of entrance of the infection was probably the roof of the attic, that is to say, directly from the tympanic cavity, and not from the antrum or cells. The age of the patient, and the presence and site of the granulations occurring in an acute suppuration, suggest that we had here a process of the meninges directly in communication with the tympanum by way of the petro-squamosal suture, while the early rigor suggests the presence of a petrosquamosal sinus which is occasionally found passing directly to the lateral sinus. On first seeing the patient his condition was such as is commonly observed in acute suppuration of the middle ear, and those phenomena pointing to cerebral irritation, if nothing more, to which the term "meningism" has been applied, were by no means so marked as one sometimes gets them in cases of this disease, especially in the children in whom even congestive changes in the optic dises may be found, which recover without complication, or at the most, with extension only to the mastoid cells and antrum.

An example of each of these will bring into relief the features of the case I have described.

I received an urgent request from a medical man to see a young woman in whom cerebral symptoms had arisen in the course of an acute middle-ear suppuration. When I arrived I learnt that she had had a shivering attack, hardly amounting to an actual rigor, the night before. The temperature had risen to $103^{\circ} \mathrm{F}$, the pulse was slow, and she had become drowsy and difficult to rouse. She was somewhat better when I saw her; the temperature was $100 \cdot 2 \mathrm{~F}$., pulse 64 , and though she was still mentally dull she answered, though slowly, when spoken to. There was only a small amount of discharge from the middle ear, through a perforation in the antero-inferior segment of the membrane. There was no sagging of the posterior superior wall of the meatus, only slight tenderness over the mastoid, and $n n$ definite symptoms of intracranial complication. After, of course, consideration of the question of operation, we decided, in view of the slight improvement, to wait, and the patient recovered without any extension of the disease.

In another case, in which meningism was fairly well marked, the mastoid became involved and on operation was found com- 
pletely excavated. Here lethargy was a marked feature, the pulse, too, was slow, and the optic discs were congested, with blurring of the edges, and this was especially noticeable on the right side, which was the side on which the ear disease was; romiting had occurred several times. The patient recovered completely after the operation on the mastoid.

Such cases are not uncommon, and one has difficulty sometimes in holding one's hand.

After the first operation on this school-boy it seemed to me that the condition of the mastoid, pointing, as it did, to the action of some strong infective process, was sufficient by its proximity to account for the cerebral symptoms, or that we had to deal with a serous meningitis due to toxic substances absorbed from the attic. The increase in the intra-cranial pressure which we noticed lent support to this view, and made me consider the question of making an opening in the dura. The further course of the case made it more than probable that this was the actual condition at that stage, and that it was later, and, it may be, aided by the curetting of the granulations in the attic, that the organisms themselves found their way into the subdural and subarachnoid spaces, with the consequences already described. In this case it would seem that lumbar puncture might have been of value both diagnostically and as a method of treatment in the early period of the case. Under similar conditions I should certainly make use of it, as I have done with advantage since reading this paper.

\title{
YASELINE OIL IN THE DRESSING OF THE RADICAL MASTOID OPERATION. ${ }^{1}$
}

\author{
By Dr. J. N. Roy, \\ Physician of the Hôtel-Dieu of Montreal (Canada).
}

For some years past the dressing of the mastoid operation has been done in several different ways. In 1902 Eeman, of Gand, in his first communication to the Belgian Oto-rhino-laryngological Society, extolled the use of boracic acid. In the following year lie returned to the same theme, and reported statistics of thirtyeight patients treated by his method.

In 1905, Mahu, of Paris, presented before the French Oto-rhinolaryngological Society a new procedure, which consisted, not in ${ }^{1}$ Paper read before the Canadian Medical Association, Montreal, September, 1907. 